\title{
Ecological restoration and recovery in the wind-blown sand hazard areas of northern China: relationship between soil water and carrying capacity for vegetation in the Tengger Desert
}

\author{
LI XinRong ${ }^{1,2^{*}}$, ZHANG ZhiShan $^{1,2}$, TAN HuiJuan ${ }^{1,2}$, GAO YanHong ${ }^{1,2}$, LIU LiChao $^{1,2}$ \& \\ WANG XinPing ${ }^{1,2}$ \\ ${ }^{1}$ Shapotou Desert Research and Experiment Station, Cold and Arid Regions Environmental and Engineering Research Institute, Chinese \\ Academy of Sciences, Lanzhou 730000, China; \\ ${ }^{2}$ Key Laboratory of Stress Physiology and Ecology in Cold and Arid Regions of Gansu Province, Lanzhou 730000, China
}

Received July 6, 2013; accepted December 27, 2013; published online April 2, 2014

\begin{abstract}
The main prevention and control area for wind-blown sand hazards in northern China is about $320000 \mathrm{~km}^{2}$ in size and includes sandlands to the east of the Helan Mountain and sandy deserts and desert-steppe transitional regions to the west of the Helan Mountain. Vegetation recovery and restoration is an important and effective approach for constraining wind-blown sand hazards in these areas. After more than 50 years of long-term ecological studies in the Shapotou region of the Tengger Desert, we found that revegetation changed the hydrological processes of the original sand dune system through the utilization and space-time redistribution of soil water. The spatiotemporal dynamics of soil water was significantly related to the dynamics of the replanted vegetation for a given regional precipitation condition. The long-term changes in hydrological processes in desert areas also drive replanted vegetation succession. The soil water carrying capacity of vegetation and the model for sand fixation by revegetation in aeolian desert areas where precipitation levels are less than $200 \mathrm{~mm}$ are also discussed.
\end{abstract}

desert areas, sand fixation by plant, succession of the artificial vegetation, soil water dynamics, carrying capacity for vegetation

Citation: $\quad$ Li XR, Zhang ZS, Tan HJ, Gao YH, Liu LC, Wang XP. Ecological restoration and recovery in the wind-blown sand hazard areas of northern China: relationship between soil water and carrying capacity for vegetation in the Tengger Desert. Sci China Life Sci, 2014, 57: 539-548, doi: $10.1007 / \mathrm{s} 11427-014-4633-2$

The areas suffering from wind-blown sand hazard events in China are distributed from longitude $75^{\circ}-125^{\circ}$ and latitude $35^{\circ}-50^{\circ}$ and form a discontinuous arc-shaped desert zone (including sandlands) from the western Tarim Basin in the west to the western Songnen Plain in the east. It traverses northwest, north and northeast-China with a length of $4500 \mathrm{~km}$ from east to west and a width of $600 \mathrm{~km}$ from south to north, crossing arid, semi-arid and sub-humid climatic zones and covering the eight largest deserts and the four largest sandlands in China [1,2]. The sandlands and the farm-

*Corresponding author (email: 1xinrong@1zb.ac.cn) ing-pastoral ecotone in eastern China, where annual precipitation is more than $250 \mathrm{~mm}$ and the desert and oasis, desert and desert-steppe transition regions to the west of the Helan Mountain, where annual precipitation is less than $200 \mathrm{~mm}$, cover about $320000 \mathrm{~km}^{2}$. They are the regions most seriously affected by desertification and sand hazards. The main prevention and control areas in China for wind-blown sand hazards are also the main areas for non-irrigated vegetation construction and ecological barrier building [3-5].

Using revegetation as a method to control sand damage in China has been practiced for nearly 60 years and is one of most successful approaches to constraining wind-blown 
sand disasters [6]. Studies have shown that sand fixation by revegetation can effectively prevent further desertification, alleviate wind-blown sand disasters and promote local habitat recovery [6,7]. However, blind and large-scale revegetation with a single species of plant in the eastern sandlands, which have a higher precipitation or in the desert areas to the west of the Helan Mountain where precipitation is lower, resulted in a decline in the groundwater levels, degradation of sand-binding vegetation and even new desertification. Furthermore, it seriously affected the ecological effects of sand-binding vegetation and the overall sustainability of the restoration [2,5].

This leads to a number of questions, such as how much water is needed for revegetation in different bio-climatic desert areas? What type of sand-binding vegetation grows at a given level of precipitation? How large scale is the natural vegetation regrowth and how effective is the vegetation construction over the longer term? All of these questions are important scientific issues faced by the national strategy on sand prevention and control. Therefore, confirmation of the soil water carrying capacity of the vegetation is an important precondition to solving these problems and is also an important requirement for sand prevention and control and ecological restoration in desert areas.

The plant-soil water relationship is the key scientific problem for ecological recovery and restoration in arid desert areas $[2,5,8]$. Soil water sourced from the atmosphere and underground water can be used by plants [9] and is the driving force that shapes vegetation patterns and processes [10]. Soil hydrological processes determine the main ecological processes, such as plant growth, vegetation succession and landscape variability [11]. Since the integrated SPAC concept was proposed by Philip (1966), the plant-soil water relationship has been an important issue in international plant ecological research [2,9] and the study of soil water carrying capacity remains at the forefront of ecological revegetation. The problem is that there have been few long-term studies on ecological and hydrological processes in revegetated systems [2,9-11]. As early as in the 1950s, when the vegetation protective system was established along the Baotou-Lanzhou railway in the sand dune area, Chinese researchers began to study the water cycle and water balance of this sand-binding vegetation system [12] and met with considerable success [13]. The long-term study was able to thoroughly investigate the soil water carrying capacity of vegetation at a given precipitation condition. This study analyzed the soil water carrying capacity of vegetation in the arid desert area, based on over 50 years of long-term monitoring and study at the Shapotou Desert Research and Experimental Station of the Chinese Academy of Sciences, which is located on the southeast edge of the Tengger Desert. The aim was to investigate ecohydrological processes and their feedback mechanisms and provide a theoretical basis for practical ecological construction and sand hazard mitigation in desert areas.

\section{Materials and methods}

\subsection{Study site}

Shapotou is part of Zhongwei City, which is located in the Ningxia Hui Autonomous Region on the southeastern fringe of the Tengger Desert $\left(37^{\circ} 32^{\prime} \mathrm{N}, 105^{\circ} 02^{\prime} \mathrm{E}\right)$. The main landscape type is high and dense reticulate chains of barchan dunes. Some psammophytes, such as the shrub, Hedysarum scoparium Fisch. Et Mey. and annual herbs, such as Agriophyllum squarrosum Moq. and Stilpnolepis centiflora Krasch., are found sporadically and cover about $1 \%$ of the area [13]. The soil water content of the moving sand dune profile (0-300 $\mathrm{cm}$ depth) is $2 \%-5 \%$ and the groundwater level lies $80 \mathrm{~m}$ below the surface and therefore cannot be used by plants. The annual mean temperature is $10.0^{\circ} \mathrm{C}$ and the extreme low and high temperatures are -25.1 and $38.1^{\circ} \mathrm{C}$, respectively. The mean annual sunshine is $3264 \mathrm{~h}$, mean annual precipitation is $186.2 \mathrm{~mm}(1956-2012)$ and annual potential evaporation is about $3000 \mathrm{~mm}$. The mean annual wind velocity is $2.9 \mathrm{~m} \mathrm{~s}^{-1}$ and annual number of days with sandstorm events is 59 . To prevent more than $40 \mathrm{~km}$ of the Baotou-Lanzhou railway bed from wind-blown sand damage (wind erosion and sand burial) and to insure its efficient operation in the Shapotou area, a revegetation protective system along the railway to prevent sand damage was gradually designed and built by the Chinese Academy of Sciences and the Department of Railways [13]. A metal fence was first erected perpendicular to the prevailing wind direction and the moving sand dunes. After the fence, $1 \mathrm{~m} \times 1 \mathrm{~m}$ straw-checkerboards were established as matrix for sand fixation. Then xerophytic shrubs (2-year-old seedlings), such as Caragana korshinskii Kom., Artemisia ordosica Krasch., H. scoparium, Caragana microphylla Lam., Calligonum arborescens Litw. and Atraphaxis bracteata A. Los., were replanted with row and line spaces of $1 \mathrm{~m} \times 2 \mathrm{~m}$ or $2 \mathrm{~m} \times 3 \mathrm{~m}$. The same method was applied in 1964, 1973, 1982 and 1992. The dunes were stabilized by replanting $16 \mathrm{~km}$ of land along both sides of railway. The revegetated zone that was built up over the years formed a revegetation protective system with a width of 500-1000 m to the north and width of $200-1000 \mathrm{~m}$ to the south of the railway. It prevents wind-blown sand damage to the railway and forms a stabilized sand-binding vegetation community. It is used as a successful example of sand damage prevention of arterial traffic around the world [13].

In 1956, Shapotou Station set up long-term monitoring plots within the north and south sides of the $16 \mathrm{~km}$ stretch of railway. Ten $10 \mathrm{~m} \times 10 \mathrm{~m}$ plots were set up in each of the revegetated areas established in the years quoted above (each area contained vegetation of a different age and had a width of $100-150 \mathrm{~m}$ and length of more than $10 \mathrm{~km}$ ). The vegetation, soil water content and climatic factors have been monitored continuously for more than 50 years [14]. 


\subsection{Methods}

The revegetated areas established in 1956, 1964 and 1982 and the moving sand dunes were selected as study sites and we chose the data recorded between 1982 and 2012 for comparison. The soil water contents were measured at three sampling points per quadrat for each plot (one plot contained 10 quadrats), i.e., 30 sampling points in total were arranged in each sand-binding area or moving sand dune. The soil water contents in the $0-300 \mathrm{~cm}$ soil profile were measured and included 16 soil layers: $0-10 \mathrm{~cm}, 10-20 \mathrm{~cm}$, $20-40 \mathrm{~cm}$ and then in increments of $20 \mathrm{~cm}$ to a depth of $280-300 \mathrm{~cm}$ [15]. Soil water contents were measured using a soil auger and the weighing method between 1982-2000 and then using a neutron probe after 2000 [13]. The volumetric soil water contents measured after 2000 were converted into gravimetric soil water contents (volumetric soil water contents/soil bulk density) in this study. Soil water contents were measured two to three times every month, but the measurements were delayed a week if precipitation occurred during the measurement period. So the data were continuous from 1982 to 2012 for each quadrat, including the reference quadrats (i.e., moving sand dunes) [15].

Precipitation was measured at the Shapotou Meteorological Station (it has operated from 1955 to the present day and is located in the sand-binding area that was established in 1956). Evapotranspiration data were collected from the 53-year-old sand-binding vegetation area and in the adjacent native steppe-desert areas. The measurements were conducted in 2009 using the eddy covariance method. Three-dimensional wind speed and ultrasound virtual temperature were measured by a three-dimensional ultrasound anemograph (CSAT-3, Campbell, USA) and the density impulses for $\mathrm{CO}_{2}$ and $\mathrm{H}_{2} \mathrm{O}$ were measured using an open type infrared gas analysis meter (Li-7500, Li-Cor Inc, USA). The evapotranspiration values were calculated from the covariances between vertical wind speeds, which were recorded using CSAT-3, and vapour concentration, measured using an Li-7500 [16].

An annual vegetation survey was also conducted between the end of September and the beginning of October at the plots used for monitoring soil water content. Coverage of shrubs (10 $\mathrm{m} \times 10 \mathrm{~m}$ plots) and herbs (five herb $1 \mathrm{~m} \times 1 \mathrm{~m}$ quadrats were randomly set up at each of the abovementioned shrub plots), species richness (average number of plant species in a quadrat) and abundance (average number of individuals per a square meter) were recorded [17]. We took the data from the Shapotou Station CERN database. Biological soil crust (BSC) coverage was measured using the point sampling method [18]. Cryptogamic species richness and biological soil crust coverage relied on the use of previous data [19], and supplement data measured in 2012.

\subsection{Statistical analysis}

In accordance with the root-systems distribution in sand- binding vegetation areas regime [20], soil water in the 0$40 \mathrm{~cm}$ layer, where herbaceous roots are concentrated, was taken as the shallow soil water contents and soil water in the 40-300 cm layer, where shrub and semi-shrub roots are mainly distributed, was taken as the deep soil water contents. Soil water contents and vegetation features (coverage, species richness and abundance) among the three sand-binding areas and the reference site (mobile dune) were compared using ANOVA and the single factor test. Correlations between soil water variation and changes in vegetation features were analyzed using SPSS software.

\section{Results}

2.1 Long-term spatiotemporal variation in soil water in sand-binding areas containing vegetation of different ages

Figure 1A shows that the soil water contents of mobile dunes responded significantly to variations in annual precipitation, which meant that they were determined by the precipitation. Mean water contents in the 0-300 cm layer of soil ranged between $1.3 \%$ and $4.5 \%$. Soil water contents increased with depth and the soil water content in the shallow layer $(0-40 \mathrm{~cm})$ was significantly lower than in the deep layer $(40-300 \mathrm{~cm})(P<0.01)$. The soil water contents in both the deep and shallow layers had a significantly positive correlation with annual precipitation $\left(R_{\text {deep layer }}^{2}=0.4312\right.$, $\left.P<0.0001 ; R_{\text {shallow layer }}^{2} 0.5721, P<0.0001\right)$.

In the early stages, after the sand-binding vegetation had been established, vegetation had a weak influence on soil water in the dunes, which was shown by the fact that soil water contents in the deep soil layer were higher than those in shallow soil layer, and that the soil water contents were determined by precipitation fluctuations (Figure 1B). Around 14-16 years after the sand-binding vegetation has been established, the soil water pattern in the sand-binding area had significantly changed. Shallow soil water increased while deep soil water tended to decline and this tendency became more obvious as the sand-binding vegetation aged. The soil water content response to precipitation also changed. The shallow soil water content had a significantly positive correlation with precipitation $\left(R^{2}=0.4783, P<\right.$ $0.0001)$, but the soil water content in the deep layer was not related to precipitation levels $\left(R^{2}=0.0942, P=0.0168\right)$.

Nearly 40 years after sand-binding vegetation had been established, the soil water pattern changed again (Figure 1C and D). The shallow soil water content was still generally higher than in the deep layer, but the soil water contents in both the shallow and deep layers began to show the same responses to variation in precipitation, i.e., precipitation directly influenced soil water contents in both the shallow and the deep layers. The deep soil water contents had also risen and had stabilized at around $1 \%$. 

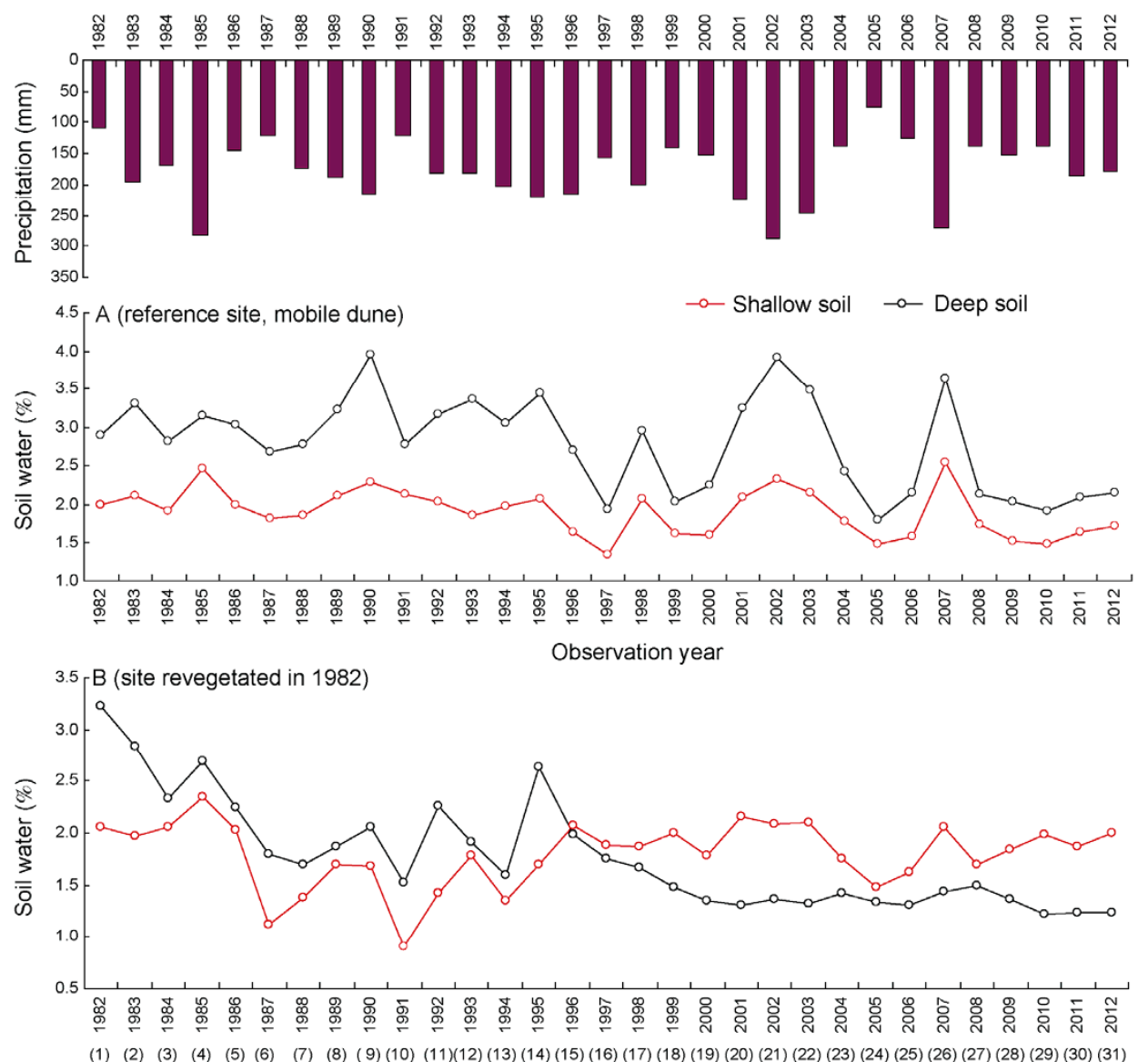

Observation year (age of sand-binding vegetation)

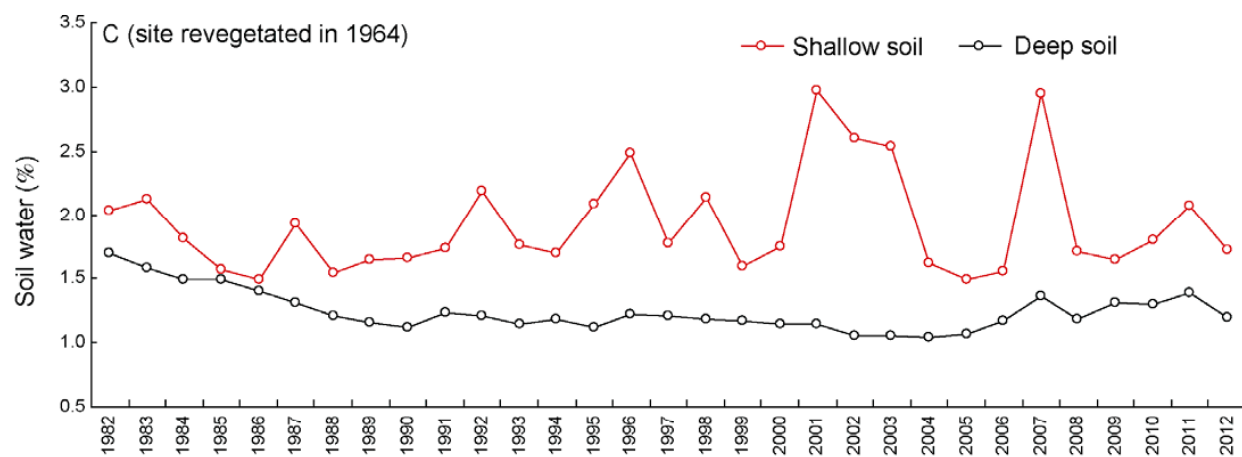

(18) (19) (20) (21) (22) (23) (24) (25) (26) (27) (28) (29) (30) (31) (32) (33)(34) (35) (36) (37) (38) (39) (40) (41) (42) (43) (44) (45) (46) (47) (48)

Observation year (age of sand-binding vegetation)

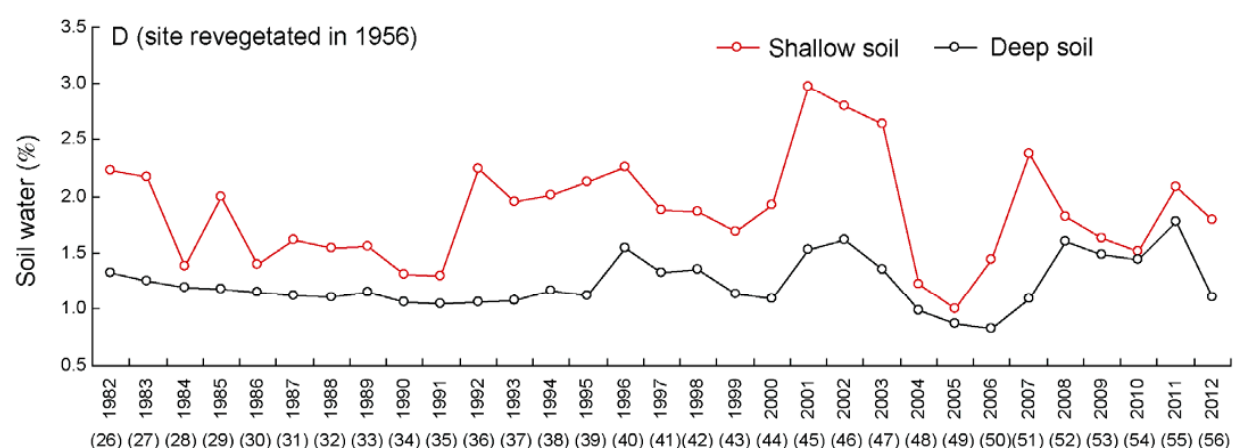

Observation year (age of sand-binding vegetation)

Figure 1 The relationships between annual precipitation and soil water content variation in vegetated areas of different ages and mobile dune areas. 


\subsection{Changes in sand-binding vegetation}

In the early stages of sand-binding vegetation development, the coverage of planted shrubs increased significantly from $3 \%$ at the 2 nd year to $35 \%$ by the 15 th year (Figure $2 \mathrm{~A}$ ). After that, shrub coverage fell gradually to $9 \%$ by the 45 th year and then remained stable at $8 \%-10 \%$ (Figure $2 \mathrm{~B}$ and C). Herbaceous coverage declined from $35 \%$ during the early stages (Figure $2 \mathrm{~A}$ ) to $12 \%$ by the 15 th year, but then increased to $30 \%-45 \%$ after 50 years. The coverage fluctuated, but generally showed an increasing trend as the sand-binding vegetation aged (Figure 2C). Around 10 years after vegetation establishment, cyanobacteria crusts (such as Hydrocoleus violacens Gom., Microcolous vaginatus Gom., Nostoc sp. and Phormidium ambgum Gom.) were dominant on the dune surface with a coverage of $10 \%-30 \%$. After 40 years, mixed crusts, composed of lichens (Collema coccophorum Tuck., Collema tenax Ach., Diploschistes muscrum Hoffm., Tomin and Endocarpon aridum P. M. McCarthy) and mosses (Bryum argenteum Hedw., Didymodon vinealis Zand., Tortula bidentata Bai Xue Liang and Tortula desertorum Broth., etc.) emerged and had a coverage of 30\%-40\%. After 50 years, the BSCs were dominated by mosses and lichens with a coverage of 50\%-60\% (Figure 3).

There were initially five planted shrub species, but only two species (C. korshinskii and A. ordosica) remained after 40 years. The abundance of $A$. ordosica fluctuated with precipitation in a similar way to the herbaceous plants and $C$. korshinskii abundance began to increase slowly after 50 years. In the early stages of sand-binding vegetation growth, some herbaceous species (such as A. squarrosum, Pugionium calcaratum Kom. and $S$. centiflora), which are native to mobile dunes, emerged. Their seeds, which accumulated in the soil seed banks, germinated rapidly and had a high coverage because the dune surfaces were initially fixed (Figure 2A), but they soon disappeared from the community composition. After 50 years, 14-16 of herbaceous species settled naturally and maintained a relatively stable species richness in the revegetated community (Figure 2B and C). Some biennial (Echinops gmelinii Turcz. and Scorzonera Capito Maxim.) and perennial species (Stipa bungenana Trin. Ex Bge.) emerged in the revegetated community, but annual species, such as Eragrostics cilianensis Link ex Vign. Lut., Setaria viridis Beauv., Bassia dasyphylla O. Kuntze and Corispermum patelliforme Iljin, dominated the herbaceous stratum. Herbaceous abundance was closely related to annual precipitation. Cryptogamic diversity of BSC species, such as algae, lichens and mosses, increased as the sand-binding vegetation aged and species richness reached saturation at 40 years after vegetation establishment (Figure 3).

\subsection{Relationship between soil water dynamics and variation in sand-binding vegetation}

From the initial revegetation stage to 15 years after revegetation, no significant correlations between soil water contents and vegetation coverage, species richness and abundance were found $\left(R_{\text {coverage }}^{2}=0.1087, P=0.03722 ; R_{\text {richness }}^{2}=\right.$ $0.0914, P=0.0255 ; R_{\text {abundance }}^{2}=0.0931, P=0.0843$ ). However, these above vegetative parameters did increase. Around 15 years after revegetation, the planted shrub coverage had declined significantly from its peak $(35 \%)$ and this was positively related to the decreasing soil water contents in the deep soil $\left(R^{2}=0.3727, P<0.0001\right)$. However, this was not the case in the shallow soil water $\left(R^{2}=0.0924, P=0.0246\right)$. Coverage and abundance of herbs were closely positively correlated to soil water contents in the shallow soil $\left(R_{\text {coverage }}^{2}=0.3917, P<0.0001 ; R_{\text {abundance }}^{2}=0.4721, P<0.0001\right)$, but not in the deep soil $\left(R_{\text {coverage }}^{2}=0.1162, P=0.0415\right.$; $R_{\text {abundance }}^{2}=0.0983, P=0.0312$ ). Species richness for herbs had an insignificant correlation with soil water contents in both the deep and shallow layers (Figure 2) and increased as the sand-binding vegetation aged. For cryptogams, the species richness, abundance and coverage of the BSCs had insignificant correlations with water contents in both the deep and shallow soil layers and they also increased as the sand-binding vegetation aged (Figure 3 ).

Around 40 years after vegetation establishment, the decreasing trend in planted shrub coverage became less obvious and stabilized at 8\%-10\%. However, C. microphylla, A. bracteata and $C$. arborescens vanished from the revegetated community. C. korshinskii can be renewed by natural seeding and its annual seedlings were always found in places where shallow soil water was higher and when rainfall was adequate in autumn. The abundance of A. ordosica seedlings was positively correlated with shallow soil water contents $\left(R^{2}=0.4326, P<0.0001\right)$. At the same time, deep soil layer water contents showed a slowly decreasing trend, which varied between $0.7 \%$ and $1.3 \%$, whereas herb species richness showed an increasing trend (Figure 2). Cryptogamic species richness in BSCs tended to be saturated, but their coverage still rose. Coverage by mosses and lichens increased significantly as the sand-binding vegetation aged and there were no obvious correlations with temporal and spatial variation in soil water contents $\left(R^{2}=0.0876\right.$, $P=0.0636$ ). Furthermore, a BSC community dominated by mosses gradually replaced the initial community dominated by cyanobacteria (Figure 3 ).

Around 50 years after the sand-binding vegetation had been established, the shrub coverage stabilized at about the $10 \%$ level and herb and crustal cryptogram coverage ranged between $35 \%$ and $45 \%$ and $50 \%$ and $70 \%$, respectively. Both shrub coverage and soil water contents in the deep soil were relatively stable. Herb species richness tended to be saturated, but their abundance was closely related to precipitation and shallow soil water contents. 

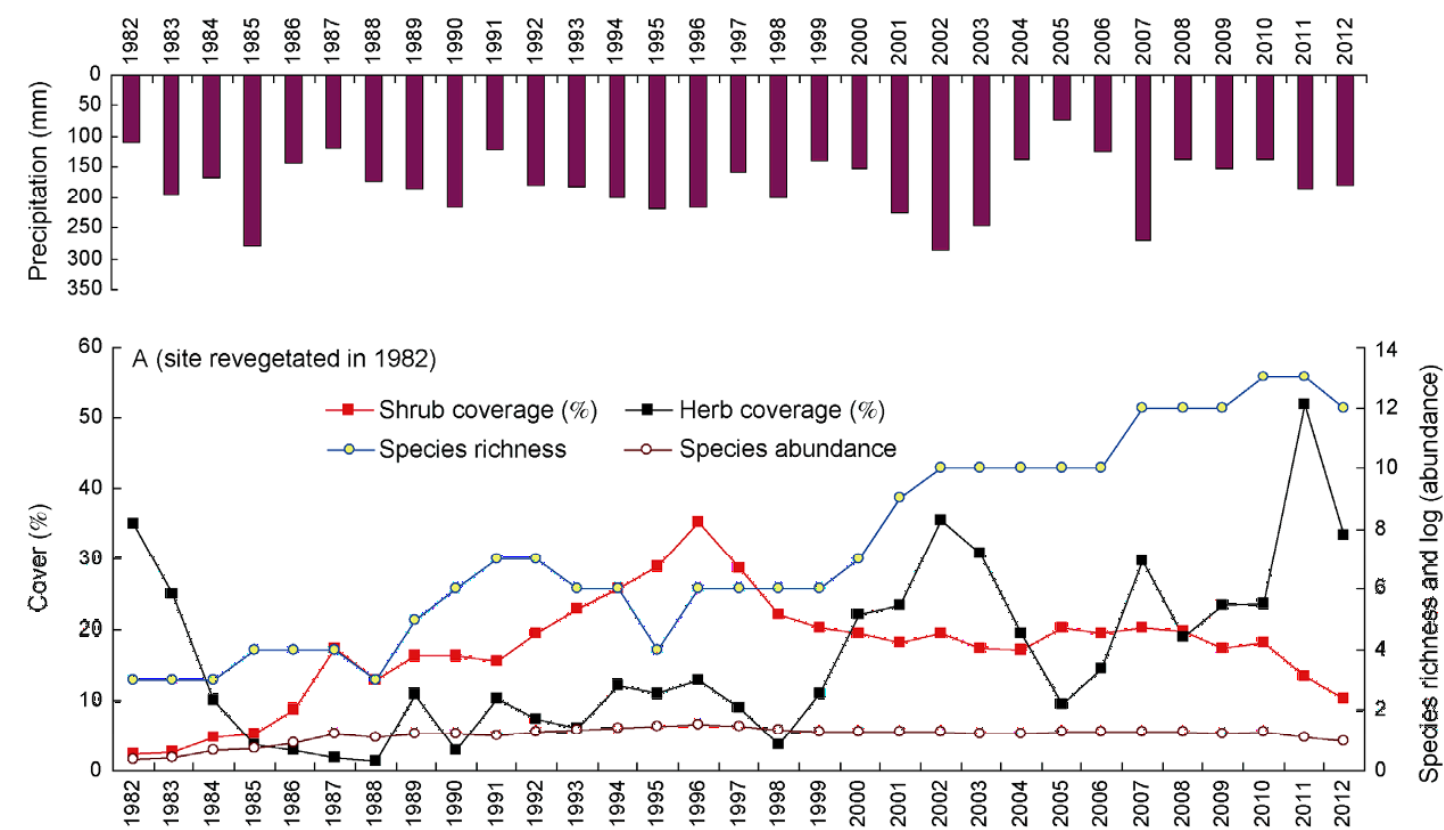

(1) (2) (3) (4) (5) (6) (7) (8) (9) (10) (11)(12)(13)(14)(15)(16)(17) (18)(19) (20) (21)(22) (23)(24) (25)(26)(27)(28) (29)(30) (31)

Observation year (age of sand-binding vegetation)

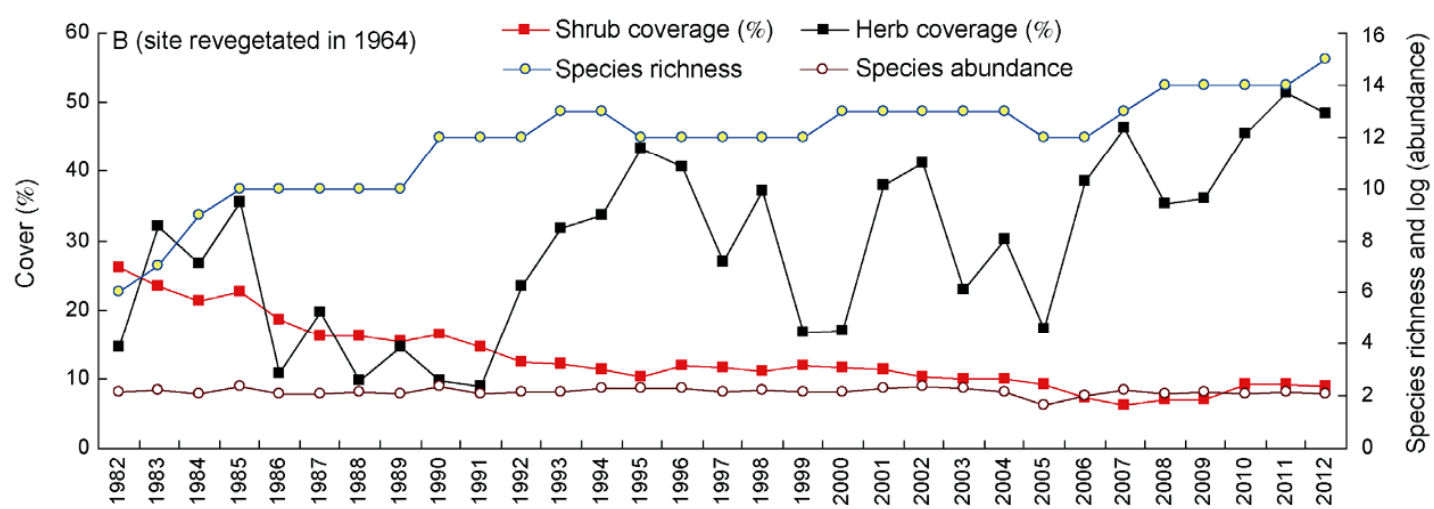

(18) (19) (20)(21)(22)(23)(24)(25) (26) (27) (28)(29) (30)(31)(32)(33)(34)(35)(36)(37)(38) (39)(40) (41) (42)(43)(44) (45)(46) (47)(48)

Observation year (age of sand-binding vegetation)

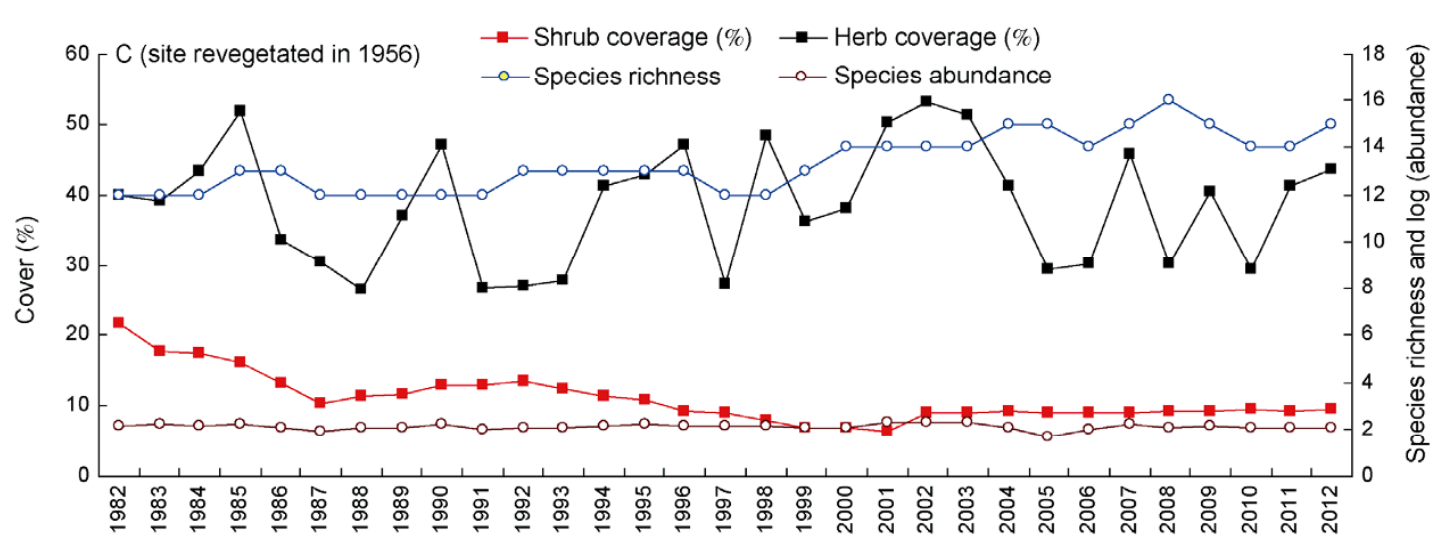

(26) (27) (28)(29) (30)(31)(32) (33) (34)(35) (36) (37) (38) (39) (40) (41)(42) (43)(44) (45)(46) (47) (48) (49)(50)(51) (52) (53) (54)(55) (56)

Observation year (age of sand-binding vegetation)

Figure 2 Changes in shrub coverage, herb coverage, species richness and in the abundance of native established plants in sand-binding vegetation of different ages and their relationship to the variation in annual precipitation. 


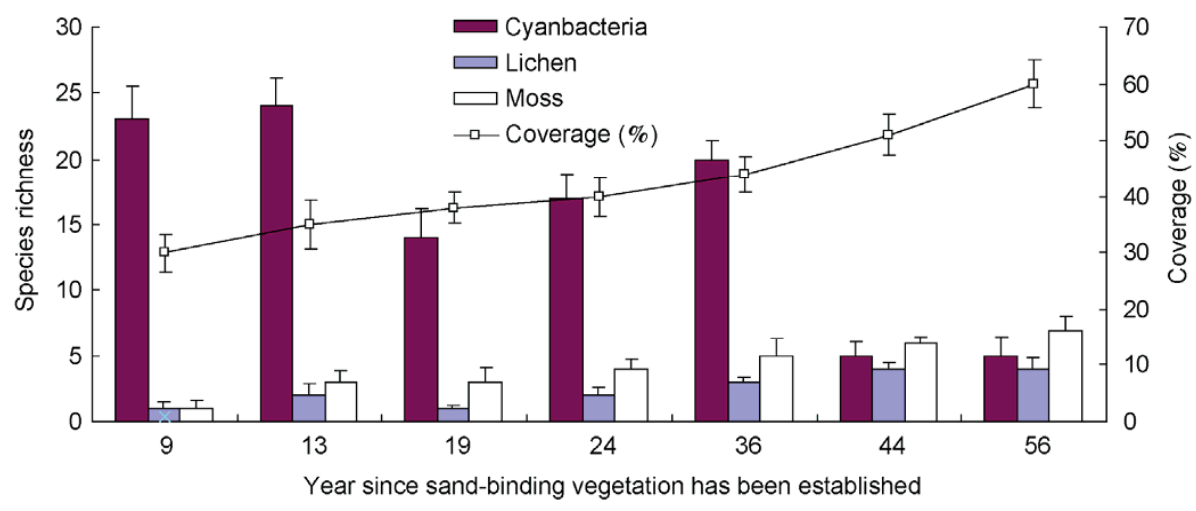

Figure 3 Changes in cryptogam species richness and crustal coverage after the revegetation of sand dunes.

\section{Discussion}

\subsection{Effects of revegetation on soil water}

Revegetation effects on soil water included direct water absorption (by roots) and support for the physiological processes behind normal growth, survival, photosynthesis and transpiration (leaves and twigs) by various individuals and populations in the community. Revegetation also had indirect effects on soil water, such as rainfall interception by the canopy $[21,22]$, spatiotemporal redistribution of precipitation infiltration by stem flow and preferential flow [23-25] and soil water redistribution by root distribution and hydraulic lift [26]. In the Shapotou area, where the groundwater level was $>60 \mathrm{~m}$ below ground, the main replenishment of soil water came from precipitation and dew had little effect, even on shallow soil water [27,28]. In the early stages of revegetation, the effects of vegetation on the spatiotemporal patterns of soil water were comparatively weak. The smaller crown and lower coverage by shrubs, herbs and BSCs, as well as a thinner layer of topsoil and BSCs [18], led to a reduced effect on interception and redistribution of precipitation by vegetation and a lower dew yield by BSCs [27]. However, as the coverage of shrubs, herbs and cryptogams increased and developed, canopy interception reached 27\% [29] and the thickening and development of BSCs (changing from cyanobacteria dominated crusts to moss dominated crusts) significantly reduced precipitation infiltration [18]. Furthermore, the increased extraction of water from the deep soil layer $(0.4-3.0 \mathrm{~m})$, due to the development of shrub root systems and not enough water replenishment because of the infiltration reduction, both resulted in significant decreases in soil water content in the deep soil layer (Figure 1B and C). The soil water-holding capacity increased as the BSCs developed and the topsoil layer thickened $[18,30]$, which meant that the precipitation residence time was extended and soil water availability appreciably increased in the shallow soil layer. Thus, with the development of sand-binding vegetation, deep soil water decreased and the availability of shallow soil water increased. In addition, shallow soil water was positively cor- related to precipitation, while deep soil water had no clear-cut correlation with precipitation and showed a decreasing trend (Figure $1 \mathrm{~B}$ and $\mathrm{C}$ ).

As the succession of sand-binding vegetation proceeded, the shrub species density decreased, which led to a reduction in rainfall interception and utilization of deeper soil water (Figure 2B and $\mathrm{C}$ ). In addition, biological disturbances to the BSC layer, including: lizard, ant and other small animal activities, increased precipitation infiltration to some extent [31]. This meant that deep soil water was replenished to a certain degree and could be maintained in a threshold range, which began to respond to precipitation (Figure 1C and D).

\subsection{Driving effects of soil water dynamics on vegetation variation}

Spatiotemporal patterns for soil water directly affected the composition and community structure of sand-binding vegetation [14]. With increasing time after dune stabilization, the initial spatiotemporal patterns for soil water in mobile dunes significantly changed, including decreased replenishment by precipitation of deep soil water and increased water-holding capacity and water availability in the shallow soil layers. This drove changes in the sand-binding vegetation. Some pioneer species with high water consumptions, such as C. arborescens, C. microphylla and A. frutescens, gradually disappeared from the community, while species with strong drought tolerances, such as $H$. scoparium, $C$. korshinskii and A. ordosica, survived at a low level and developed the ability to self-regulate. The sand-binding vegetation evolved into a stable community that was dominated by herbaceous species and had a lower coverage of $C$. korshinskii and A. ordosica. Studies by $\mathrm{Li}$ et al. [17] on the dynamics of sand-binding vegetation supported the conclusion that variations in soil water drove vegetation succession. Deep soil water significantly decreased around 15 years after sand-binding vegetation had been established. The community had entered a period where the species turnover rate was at a maximum, i.e., the community domi- 
nated by the original single shrub synusium was replaced by a community dominated by a herbaceous synusium. After 40 years, deep soil water tended to be stable. Sand-binding vegetation succession had entered a stage with a rapid species turnover rate and a number of cryptogams occurred in the stabilized dunes and formed a complex community. A multi-synusium and mixed community of sand-binding vegetation formed that was composed of a few shrubs and a large number of herbs and cryptogams [17]. The increased availability of shallow soil water enhanced germination, establishment and reproduction of herbs with shallow root distributions [32], which resulted in the expansion of herb cover. The number of $\mathrm{C} 4$ plants also increased rapidly in the community. The coverage and abundance of herbaceous species were closely related to precipitation. Although succession of the BSCs was not directly related to soil water and mainly depended on dust deposition and soil stability variation [30], they did affect the redistribution of soil water, especially: infiltration [18,33], dew deposition [27,28] and soil evaporation [34,35]. The ecological (soil stabilization, improved aggregate structure, nitrogen fixation and carbon sequestration) and the hydrological functions performed by BSCs made them an important component of the stable composition of sand-binding vegetation [36].

\subsection{Soil water carrying capacity for vegetation in de- sert areas}

As an important basis of evaluating revegetation, the vegetation soil water carrying capacity could be defined as the maximal load of artificial vegetation for a given soil water condition and can also be quantified by relevant vegetation attributes. Where the annual precipitation is less than 200 $\mathrm{mm}$ and groundwater is unavailable to plants, the relative stable quantitative features of vegetation supported by $2 \%-5 \%$ soil water content in the dunes could be described as the soil water carrying capacity for the vegetation.

Data from more than 50 years of continuous variation in soil water in the sand dunes after revegetation showed that the stable sand-binding vegetation was composed of shrubs (10\% cover), herbs $(30 \%-40 \%$ cover) and cryptogams (40\%-60\% cover) in the Shapotou area. The sand-binding vegetation was dominated by herbs and cryptogams, with a total coverage of $40 \%-60 \%$. Moreover, the ratio of annual evapotranspiration and precipitation $(\mathrm{ET} / \mathrm{P})$ in the vegetation-soil systems (Figure 4), showed that the ratio in the 50 year revegetated area $(\mathrm{ET} / \mathrm{P}=1.03)$ was close to that in the natural vegetation area $(\mathrm{ET} / \mathrm{P}=1.18)$ and was larger than the ratio calculated for the earlier stages [13]. The spatial pattern of vegetation also changed from a uniform distribution to a patchy distribution [15]. This showed that the water balance of the artificial vegetation was more stable after 50 years.

Consequently, the soil water carrying capacity of the vegetation should be limited by a given soil water content and should be expressed by stable and sustained vegetation attributes (dominant species can be self-regulating) that are within a certain threshold range. These attributes include: vegetation composition (plant life forms, ecotypes or functional groups), structure (synusium structure) and spatial pattern. The difference in the spatial pattern of the vegetation was especially important when comparing the artificial vegetation and natural vegetation and was due to long-term adaptation to environmental conditions, especially to water

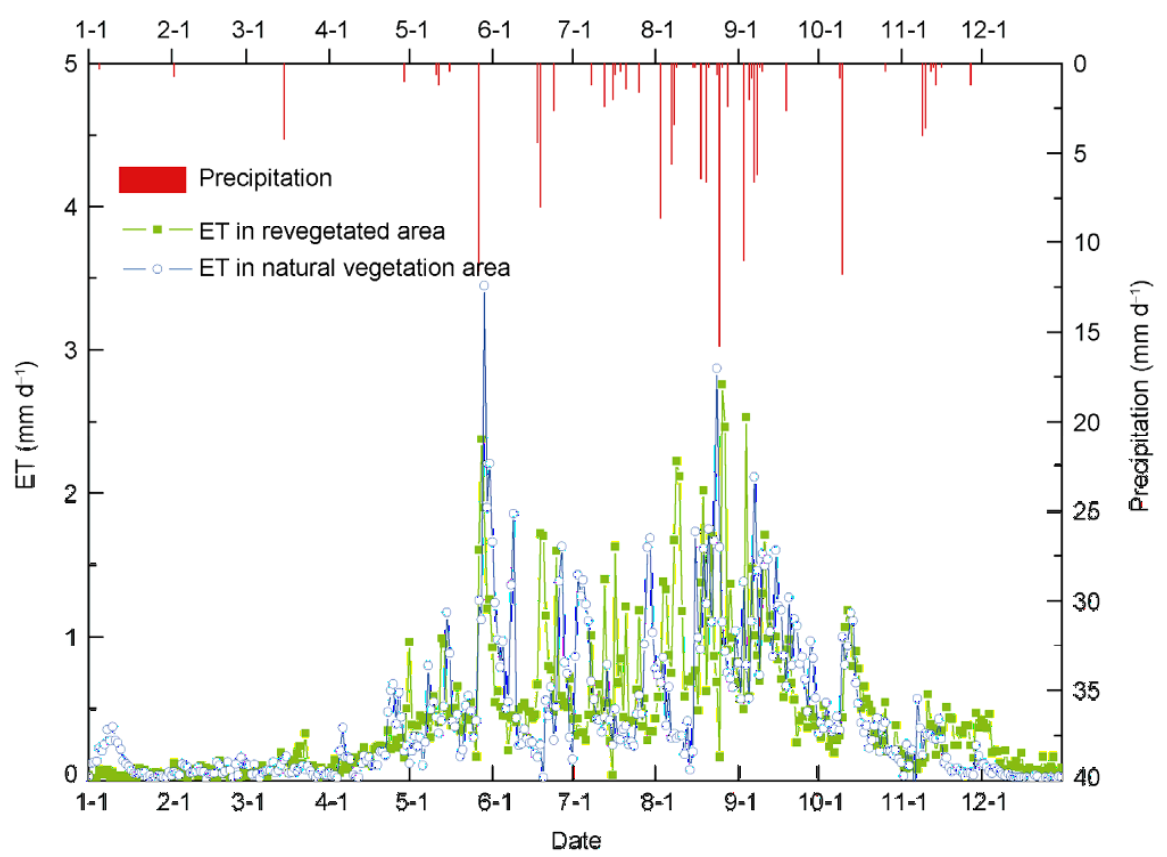

Figure 4 Evapotranspiration in the 50-year-old sand-binding vegetation plots and the adjacent natural desert steppe and its relationship to rainfall variation over a given observation period. 
availability. Discontinuous and non-uniform patterns are important vegetation traits in arid areas [37-39], whereas the establishment of new vegetation often begins with uniform and regular replanting. Hence, the soil water carrying capacity for vegetation could be expressed by a composite function that contained soil water content and above ground vegetation parameters. Based on this study, desert areas that are characterized by an annual precipitation of less than 200 $\mathrm{mm}$, soil water contents of $2 \%-5 \%$ and unavailable groundwater, the coverage of shrubs, herbs and cryptogams in the sand-binding revegetation should account for about $10 \%, 35 \%$ and less than $60 \%$, respectively and shrubs should be patchy distributed. Although quantitative expression and the modeling of vegetation soil water carrying capacity are still in their initial phases, their scientific definitions are of great significance to national strategies when it comes to sand hazard prevention and control in the future.

\section{Conclusion}

The establishment of sand-binding vegetation changed the original water balance and spatiotemporal patterns of soil water in the dune areas. Changes in soil hydrological processes drove the succession of artificial vegetation, i.e., variations in composition, structure and spatial distribution of the vegetation were long-term adaptations to hydrological processes. When another vegetation-soil water balance was achieved, the formation of the stable vegetation reflected the soil water carrying capacity of the new precipitation conditions. This study shows that it is important to consider the vegetation soil water carrying capacity when planning revegetation and ecological restoration programs in wind-blown sand disaster areas. The stable and sustainable characteristics of vegetation and the soil water balance were dependent on the soil water carrying capacity. The vegetation spatial patterns were also found to be important. In the Shapotou area of the Tengger Desert, the establishment of shrub-herb-cryptogam sand-binding vegetation with the coverage of shrubs, herbs and cryptogams covering about $10 \%, 35 \%$ and $60 \%$ of the land, respectively, reflected the maximum soil water carrying capacity of the vegetation. Thus, revegetation in this area in the future should follow the principle that the total coverage of shrub-herbcryptogam synusiums does not exceed the above threshold, which is also an important prerequisite if vegetation stability and sand-binding benefits are to be sustainable.

This work was supported by the National Basic Research Program of China (2013CB429906).

1 Zhu ZD, Liu S. Sandy Desertification Process and Its Combating Regionalization in Northern China. Beijing: Chinese Forestry Press, 1981

2 Li XR, Zhang ZS, Huang L, Wang XP. Review of the ecohydrologi- cal processes and feedback mechanisms controlling sand-binding vegetation systems in sandy desert regions of China. Chin Sci Bull, 2013, 58: 397-410

3 Wang T, ed. Desert and Desertification in China. Shijiazhuang: Hebei Science \& Technology Publishing House, 2003. 3-34

4 Ministry of Water Resources of China, Chinese Academy of Sciences, Chinese Academy of Engineering. Chinese Soil Water Loss Control and Ecological Safety (in Chinese). Beijing: Science Press, 2010

5 Sun HL, Zhang RZ. Zonal Theory and Practice in Ecological Environment Construction in China. Beijing: Science Press, 2004

6 Le Houérou HN. Restoration and rehabilitation of arid and semiarid Mediterranean ecosystems in North Africa and West Asia: a review. Arid Soil Res Rehab, 2000, 14: 3-14

7 State Forestry Administration, China. A Bulletin of Status Quo of Desertification and Sandification in China, 2011

8 Cable JM, Huxman TE. Precipitation pulse size effect on Sonoran Desert soil microbial crusts. Oecologia, 2004, 141: 317-324

9 Wang XP, Kang ES, Zhang JG, Li XR. Soil moisture dynamics in an artificially re-vegetated desert area. Adv Water Sci, 2004, 15: 216-222

10 Noy-Meir I. Desert ecosystem structure and function, Hot Deserts and Arid Shrublands. In: Evenari M, Noy-Meir I, Goodall DW, eds. Ecosystems of the World. Elsevier, 1985, 12A: 93-103

11 Eagleson PS. Ecohydrology: Darwinian Expression of Vegetation Form and Function. Cambridge: Cambridge University Press, 2002

12 Li MG, Chen LX, Chen WR. The water problem in sand-fixed afforastation along Zhongwei section of Baotou-Lanzhou railway in the Tengger Desert. Chin Sci Bull, 1958, 8: 249-251

13 The Shapotou Desert Research Experimental Station, Lanzhou Desert Research Institute, CAS. Principles and Measures for BaotouLanzhou Railway Sand-fixing at Shapotou Section. Yinchuan: Ningxia People Press, 1991

14 Li XR, Kong DS, Tan HJ, Wang XP. Changes in soil and in vegetation following stabilisation of dunes in southeastern fringe of the Tengger Desert, China. Plant Soil, 2007, 300: 221-231

15 Li XR, Ma FY, Xiao HL, Wang XP, Kim KC. Long-term effects of revegetation on soil water content of sand dunes in arid region of northern China. J Arid Environ, 2004, 57:1-16

16 Kosugi Y, Katsuyama M. Evapotranspiration over a Japanese cypress forest. II. Comparison of the eddy covariance and water budget methods. J Hydrol, 2007, 334: 305-31

17 Li XR, Zhang JG, Liu LC, Chen HS, Shi QH. Plant diversity in the process of succession of artificial vegetation types and environment in an arid desert region of China. Acta Phytoecol Sin, 2000, 24: 257-261

18 Li XR, Tian F, Jia RL, Zhang ZS, Liu LC. Do biological soil crusts determine vegetation changes in sandy deserts? Implications for managing artificial vegetation. Hydrol Proc, 2010, 24: 3621-3630

19 Li XR, Xiao HL, Zhang JG, Wang XP. Long-term ecosystem effects of sand-binding vegetation in the Tengger Desert, Northern China. Restr Ecol, 2004, 12: 376-390

20 Liu YX, Li YJ, Yang XL. Roots of desert plants. In: Selected Papers of The Shapotou Desert Science Station. Yinchuan: Ningxia People Press, 1988. 1-14

21 Huang L, Zhang ZS, Li XR. Sap flow of Artemisia ordosica and the influence of environmental factors in a revegetated desert area: Tengger Desert, China. Hydrol Proc, 2010, 24: 1248-1253

22 Wang XP, Zhang YF, Hu R, Pan YX, Berndtsson R. Canopy storage capacity of xerophytic shrubs in Northwestern China. J Hydrol, 2012, 454-455: 152-159

23 Tromble JM. Water interception by two arid land shrubs. J Arid Environ, 1988, 15: 65-70

24 Martinez-Meza E, Whitford WG. Stemflow, throughfall and channelization of stemflow by roots of three Chihuahuan desert shrubs. J Arid Environ, 1996, 32: 271-287

25 Wang XP, Wang ZN, Berndtsson R, Zhang YF, Pan YX. Desert shrub stemflow and its significance in soil moisture replenishment. Hydrol Earth Syst Sci, 2011, 15: 561-567

$26 \mathrm{Xu} \mathrm{H}, \mathrm{Li} \mathrm{Y}$. Water-use strategy of tree central Asian shrubs and their 
responses to rain pulse events. Plant Soil, 2006, 285: 5-17

27 Liu LC, Li SZ, Duan ZH, Wang T, Zhang ZS, Li XR. Effects of microbiotic crusts on dew deposition in the restored vegetation area at Shapotou, northwest China. J Hydrol, 2006, 328: 331-337

28 Pan YX, Wang XP, Zhang YF. Dew formation characteristics in a revegetation-stabilized desert ecosystem in Shapotou area, Northern China. J Hydrol, 2010, 265-272

29 Wang XP, Li XR, Zhang JG, Zhang ZS, Berndtsson R. Measurement of rainfall interception by xerophytic shrubs in re-vegetated sand dunes. Hydrolog Sci J, 2005, 50: 897-910

30 Li XR, He MZ, Duan ZH, Xiao HL, Jia XH. Recovery of topsoil physicochemical properties in revegetated sites in the sand-burial ecosystems of the Tengger Desert, northern China. Geomorphology, 2007, 88: 254-265

31 Li XR, Jia RL, Chen YW, Huang L, Zhang P. Association of ant nests with successional stages of biological soil crusts in the Tengger Desert, Northern China. Appl Soil Ecol, 2011, 47: 59-66

32 Li XR. Influence of variation of soil spatial heterogeneity on vegetation restoration. Sci China Ser D-Earth Sci, 2005, 48: 2020-2031
33 Eldridge DJ, Zaady E, Shachak M. Infiltration through three contrasting biological soil crusts in patterned landscapes in the Negev, Israel. Catena, 2000, 40: 323-336

34 Liu LC, Song YX, Gao YH, Wang T, Li XR. Effects of microbiotic crusts on evaporation from the revegetated area in a Chinese desert. Aust J Soil Res, 2007, 45: 422-427

35 Zhang ZS, Liu LC, Li XR, Zhang JG, He MZ, Tan HJ. Evaporation properties of a revegetated area of the Tengger Desert, North China. J Arid Environ, 2008, 72: 964-973

36 Li XR. Study on eco-hydrology of desert biological soil crusts. Beijing: High Education Press, 2012

37 Miriti MN. Twenty years of changes in spatial association and community structure among desert perenials. Ecology, 2007, 88: 1177-1190

38 Kéfi S, Rietkerk M, Alados CL, Pueyo Y, Papanastasis VP, ElAich A, de Ruiter PC. Spatial vegetation patterns and imminent desertification in mediterranean arid ecosystems. Nature, 2007, 449: 213-217

39 Klausmeier CA. Regular and irregular patterns in semiarid vegetation. Science, 1999, 284: 1826-1828

Open Access This article is distributed under the terms of the Creative Commons Attribution License which permits any use, distribution, and reproduction in any medium, provided the original author(s) and source are credited. 